\title{
Analysis of Sudden Cardiac Arrest during Marathon Races in Japan
}

\author{
Toru Shirakawa ${ }^{1,2}$, Hideharu Tanaka2,3*, Tomoya Kinoshi ${ }^{3,4}$, Shota Tanaka ${ }^{3}$, Hiroshi Takyu ${ }^{2}$ \\ ${ }^{1}$ Japan Emergency Medical System Co. Ltd., Miyazaki, Japan \\ ${ }^{2}$ Graduate School of Emergency Medical System, Kokushikan University, Tama, Japan \\ ${ }^{3}$ Research Institute of Disaster Management and EMS, Kokushikan University, Tama, Japan \\ ${ }^{4}$ Department of Sport and Medical Science, Faculty of Physical Education, Kokushikan University, Tama, Japan \\ Email: shirakawa@jems.co.jp, ^hidetana@kokushikan.ac.jp, maezumi@kokushikan.ac.jp, tanakamedical24@gmail.com, \\ takyu@kokushikan.ac.jp
}

How to cite this paper: Shirakawa, T., Tanaka, H., Kinoshi, T., Tanaka, S. and Takyu, H. (2017) Analysis of Sudden Cardiac Arrest during Marathon Races in Japan. International Journal of Clinical Medicine, 8, 472-480.

https://doi.org/10.4236/ijcm.2017.87044

Received: June 25, 2017

Accepted: July 25, 2017

Published: July 28, 2017

Copyright $\odot 2017$ by authors and Scientific Research Publishing Inc. This work is licensed under the Creative Commons Attribution International License (CC BY 4.0).

http://creativecommons.org/licenses/by/4.0/

\begin{abstract}
Objective: Increased number of runners in Japan has been one reason for increasing the risk of cardiac arrest during marathon races. The purpose of the study was to examine 1) the incidence of cardiac arrest during marathon races held in the past in Japan, 2) the characteristics of runners with cardiac arrest, 3 ) the effectiveness of public access defibrillation (PAD) use for cardiac arrest cases. Methods: We examined the incidence of the cardiac arrest during marathon races in Japan from the medical records of marathon races that Kokushikan University provided in the past five years. Also, we analyzed cardiac arrests occurred in Japan in the past 15 years between 1999 and 2013. Results: The incidence rate of cardiac arrest was 2.18 per 100,000 participants. As shown in Table 1, the incidence rates were 2.00 per 100,000 participants in full marathon and 2.50 per 100,000 participants in half-marathon. A total of 63 cardiac arrests occurred in the past 15 years, and the number of incidents has been increasing every year. Among 63 cardiac arrest cases, the mean age was $45.3 \pm 14.9$ years old and $93.7 \%$ (59/63 cases) were in males. Eighty-three percentage of cardiac arrest cases applied AED (20/24 cases) were the shockable rhythm. In terms of the survival rate, there was a statistically significant difference between the cases where both bystander CPR and PAD were delivered and the cases where the only bystander CPR took place without PAD (95.0\% vs. $47.1 \% ; p<0.05$ ). In Japan, the case of the PAD use during marathon races has been increasing since the use of AED was permitted for public citizens in 2004. Conclusions: Performing PAD on the scene during marathon races could be expected to be higher in the survival rate. Creating a medical support system is needed to handle sudden cardiac arrest rapidly in order to perform early bystander CPR and PAD.
\end{abstract}




\section{Keywords}

Sudden Cardiac Arrest, Marathon Race, PAD, Bystander CPR

\section{Introduction}

In recent years, marathon has been not only categorized within competitive sports as top athletes run in the Olympic games, but also spread as a popularized sport. In fact, the number of runners and marathon races has been gradually increasing every year.

It is thought that increasing the number of competitive marathon runners has a certain efficacy of promoting good health, but, at the same time, the risk of those runners' sudden cardiac arrest occurrence during marathon races has also been increasing. Kuroyanagi et al. reported 534 cases of sudden death in sports occurred in Tokyo prefecture between 1948 and 1999 and the cardiac arrests occurred the most in running as there were 118 cases during running [1]. In fact, seven cardiac arrest cases were reported from the past 10 Tokyo Marathon races, which have been held between 2007 and 2016 [2].

The medical support system for those marathon races has been changed. As the use of AED was permitted for public citizens in 2004, races implemented AED has been increasing in Japan. In fact, some cases of AED use for cardiac arrest during marathon have been reported. However, the implementation of AED for marathon races leading to the improvement on the survival rate of cardiac arrest in marathon is not clearly known. In terms of the incidence rate of cardiac arrest during marathon races, Kim et al. and Hart reported 0.54 per 100,000 participants suffered from cardiac arrests during marathon races in the U.S. between 2000 and 2010 [3] [4]. Especially in the U.S., 1.01 per 100,000 participants suffered in full marathon, and 0.27 per 100,000 participants suffered in half-marathon [3] [4]. According to the study by Pedoe et al., the incidence rate of the cardiac arrest on London Marathon was 2.17 per 100,000 participants in the past 26 years between 1981 and 2006 [5]. Moreover, regarding the characteristics of runners with cardiac arrests, $86.4 \%$ (51/59 cases) were occurred in males [3] [4], as well as other research indicated that males had more tendency to become cardiac arrests [6]. However, there is no study that has been reported about its characteristics in Japan.

The purpose of this study was to see the incidence of the cardiac arrest occurrence, characteristics of runners with cardiac arrest and the effectiveness of defibrillation by AED. We analyzed the cardiac arrest cases during marathon races held in Japan.

\section{Method}

\subsection{Study Design}

A nationwide retrospective study of cardiac arrests during marathon races. 


\subsection{The Method of How to Calculate the Incidence of the Cardiac Arrests during Marathon Races}

There were a total of 18 full marathons and 39 half-marathons that Kokushikan University provided the medical supports between April 2008 and March 2013. We investigated the total number of runners applying from either official announcement on the race website or interviewing to the marathon race committee. We also investigated the numbers of cardiac arrests from the medical support records and calculated the incidence rate of cardiac arrest during those marathon races.

\subsection{The Method of How to Collect Data of Cardiac Arrests Occurred during Marathon Races and Analysis Items}

We extracted cardiac arrests occurring where marathon races was held in Japan during 15 years between 1999 and 2013, from the Asahi Shimbun online article database "Kikuzo II Visual for Libraries ${ }^{\circledR 》}$, the internet, and journal articles. For each cardiac arrest case, we asked each race committee for the detailed examination.

On questionnaire, we asked the detail of runners who went to cardiac arrest, such as sex, age, the type of race, the location of cardiac arrest occurrence, the time of race started, the time of when cardiac arrest occurred, bystander CPR, AED application, defibrillation by AED, and outcome.

\subsection{Statistical Analysis}

We used Microsoft ${ }^{\circledR}$ Excel $^{\circledR}$ for data analysis. Chi-Square test was used to compare the survival rate, and level of significance was set at 0.05 .

\subsection{Consent and Ethical Considerations of the Study}

We gave a clear explanation to subjects regarding the purpose of the study for each question. We made sure that subjects will not take disadvantages when they refused to participate in the study. We followed the Act of the Protection of Personal Information and we carefully handled personal information as all individual information will not go to the public. The study was approved by the Institutional Review Board at Kokushikan University.

\section{Result}

\subsection{The Incidence of the Cardiac Arrests during Marathon Races (Table 1)}

Kokushikan University provided the medical coverage for a total of 57 races (18 full marathons and 39 half-marathons) between April 2008 and March 2013. The total number of runners were 459,479 (299,691 people in full marathon and 159,788 in half-marathon) and 10 cardiac arrests occurred (6 cases in full marathon and 4 cases in half-marathon). The mean age of 10 cases was $45.8 \pm 17.8$ years old, and all 10 cases occurred in male.

The incidence of cardiac arrest was 2.18 per 100,000 participants. As shown in 
Table 1. Cardiac arrest incidence and type of marathon.

\begin{tabular}{cccc}
\hline & No of Attendant & No. of Cardiac Arrest & Incidence (per 100,000) \\
\hline Overall & 459,479 & 10 & 2.18 \\
Full Marathon & 299,691 & 6 & 2 \\
Half Marathon & 159,788 & 4 & 2.5 \\
\hline
\end{tabular}

Table 1, the incidence was 2.00 per 100,000 participants in full marathon, and 2.50 per 100,000 participants in half-marathon.

\subsection{The Number of Cardiac Arrests during Marathon Races in Japan}

We extracted 63 cardiac arrest cases (26 cases in full marathon and 37 cases in half-marathon) from the past 15 years between 1999 and 2013. We divided into the three sections for every-five-year. There were 18 cases between 1999 and 2003, 22 cases between 2004 and 2008, and 23 cases between 2009 and 2013. The number of cardiac arrests gradually increased.

\subsection{Background Data of Cardiac Arrest Cases during Marathon Races in Japan (Table 2)}

Males were accounted for $93.7 \%$ (59/63 cases) of cardiac arrests during marathon races. Cardiac arrest occurred within the wide range as the mean age was $45.3 \pm 14.9$ years old (Min: 20-year-old; Max: 70-year-old).

In order to analyze the location of cardiac arrest occurrence, we assumed $0 \%$ of the race at the start line and $100 \%$ at the finish line. For the full marathon, the majority of cardiac arrests occurred at the $50 \%-74 \%$ point and the $75 \%-99 \%$ point. For the half-marathon, $75 \%-99 \%$ point and the finish line had the majority of cases.

In terms of the speed of runners who went cardiac arrest, the average speed was $10.8 \pm 3.2 \mathrm{~km} / \mathrm{h}$ (Min: $6 \mathrm{~km} / \mathrm{h}$; Max: $21.6 \mathrm{~km} / \mathrm{h}$ ). The majority of cardiac arrests occurred for runners who run under $9.9 \mathrm{~km} / \mathrm{h}$ in full marathon, and runners who run with $10.0-14.9 \mathrm{~km} / \mathrm{h}$ in half-marathon.

\subsection{The Effectiveness of AED and Survival Rate on Cardiac Arrests during Marathon Races}

The survival rate of cardiac arrests during marathon races was 54.0\% (34/63 cases). However, the every-five-year survival rate was increased as follows: $22.2 \%$ (4/18 cases) between 1999 and 2003, 63.6\% (14/22 cases) between 2004 and 2008, and $69.9 \%$ (16/23 cases) between 2009 and 2013. We highlighted the increased survival rate after 2004, because AED was implemented for marathon races.

\subsection{The Survival Rate of the Use of PAD}

Within the 47 cases performed bystander CPR on the scene, we analyzed the survival rate after one-month on 37 cases of them, which were known to be if the 
Table 2. Patients background.

Overall $(n=63)$, Full Marathon $(n=26)$, Half Marathon $(n=37)$,

(\%)

(\%)

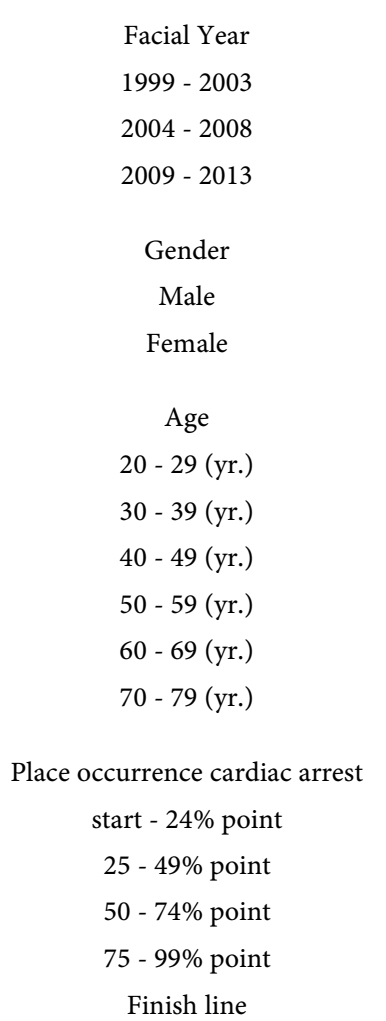

Speed of cardiac arrest runner

$\sim 9.9 \mathrm{~km} / \mathrm{h}$

$10.0-14.9 \mathrm{~km} / \mathrm{h}$

$15.0 \mathrm{~km} / \mathrm{h} \sim$

14, (22.2)

$10,(15.9)$

$11,(17.5)$

$16,(25.4)$

$10,(15.9)$

$2,(3.2)$

$(\mathrm{n}=56)$

4, (7.1)

4, (7.1)

$11,(19.6)$

$18,(32.1)$

$19,(33.9)$

$(\mathrm{n}=38)$

$18,(47.4)$

16, (42.1)

$4,(10.5)$

8, (30.8)

$10,(27.0)$

$8,(30.8)$

$14,(37.8)$

10, (38.5)

13, (35.1)

$\%)$

$0,(0.0)$

33, (89.2)

4, (10.8)

3, (21.4)

11, (29.7)

3, (21.4)

7, (18.9)

6, (23.1)

5, (13.5)

9, (34.6)

7, (18.9)

4, (15.4)

6, (16.2)

$1,(3.8)$

$1,(2.7)$

$(\mathrm{n}=23)$

$(\mathrm{n}=33)$

2, (8.7)

2, (6.1)

1, (4.3)

3 , (9.1)

$1,(3.0)$

$10,(43.5)$

9, (27.3)

$9,(39.1)$

18, (54.5)

$1,(4.3)$

$(\mathrm{n}=22)$

( $\mathrm{n}=16)$

7, (31.8)

11, (68.8)

11, (50.0)

5, (31.3)

4, (18.2)

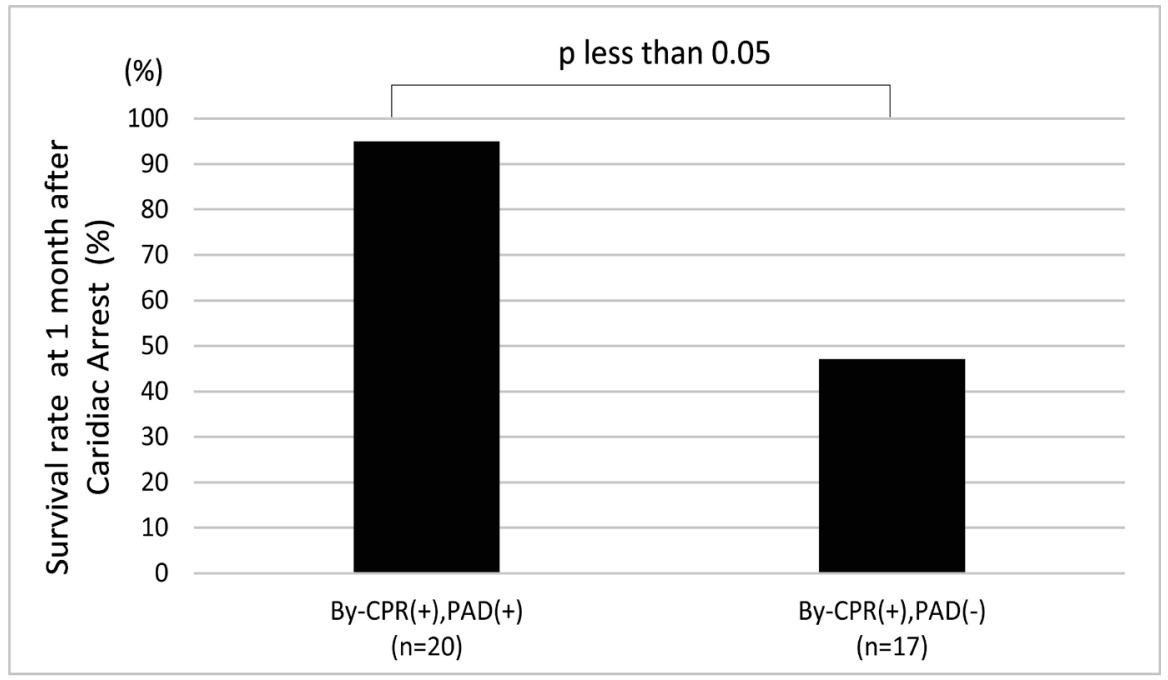

By- CPR: Bystander CPR

PAD: Public access difibrillation

Figure 1. Survival rate between PAD and non PAD patients. 
defibrillation by AED on the scene was used. Twenty cases were given defibrillation and 17 cases were not. The survival rate after one-month was 95.0\% (19/20 cases) when the defibrillation was administered, and $47.1 \%$ (8/17 cases) when the defibrillation was not administered. A significant difference was found between the presence or absence of defibrillation by AED ( $\mathrm{p}<0.05)$ (Figure 1).

The details of 20 cases of the presence of defibrillation were as follows: zero cases between 1999 and 2003, eight cases between 2004 and 2008, and 12 cases between 2009 and 2013. The case with the use of defibrillation was significantly increased after 2004.

\subsection{Precision of Defibrillation with Runners with Cardiac Arrest}

Twenty-seven cases were identified with the application of AED on the scene. Of which, 24 cases were known to be if the defibrillation by AED on the scene was used, and the percentage of administering defibrillation was $83.3 \%$ (20/24 cases). From the analysis, we identified that $83 \%$ of runners with cardiac arrest during marathons races would have shockable rhythm, ventricular fibrillation or pulseless ventricular tachycardia.

\section{Discussion}

From this study, the incidence of cardiac arrest during marathon races in Japan was 2.18 per 100,000 participants. This is quite similar to the study from England (2.17 per 100,000 participants), and we have four times greater than the study from the U.S. (0.54 per 100,000 participants) [3] [4] [5]. In terms of the incidence of cardiac arrests during marathon races, cardiac arrests occurred quite often in Japan compared to the other countries. We thought the incidence rate of cardiac arrest was influenced by increasing the number of competitive marathon runners and a wide range of runner population, especially in elderly. From the previous study, 40 cardiac arrests occurred in full marathons and 19 cardiac arrests occurred in half-marathons among 10.9 million participants [3] [4]. Although the incident of cardiac arrest per 100,000 was higher in full marathons from the study by Kim et al. and Hart [3] [4], our study indicated half-marathons was higher in danger as we found 2.0 per 100,000 in full marathons and 2.5 in half-marathons. This is because there are a larger number of half-marathons held in Japan than full marathons. Since half-marathons has a shorter distance, the higher percentage of runner who is not well-trained.

Regarding the characteristics, cardiac arrest was occurred not only with elderly, but also with a wide range of age group between 20's and 70's. Males were accounted for $93.7 \%$ (59/63 cases) from our study, and also Kim et al. reported $86.4 \%$ and Hart reported $86 \%$ of cardiac arrest cases occurred in males [3] [4]. As well as Waite et al. also found males are more in danger to become cardiac arrest [6], we conclude that males were one of risk factors of cardiac arrest during marathon race from the result of our study and the previous study.

In terms of location, we found that the majority of cardiac arrest occurred in 
the second half of the race. Different higher risk points existed between full marathon and half-marathon. For full marathon, $50 \%-74 \%$ point were the most, followed by $75 \%$ - $99 \%$ point. For half-marathon, the finish line was the most, followed by $75 \%$ - 99\% point. Cardiac arrests at the finish line were reported in the U.S. [7]. From our result, we need to consider the higher risk of location and put medical coverage for these spots.

The mean speed of runners who went to cardiac arrest was $10.8 \pm 3.2 \mathrm{~km} / \mathrm{h}$ (Min: $6 \mathrm{~km} / \mathrm{h}$; Max: $21.6 \mathrm{~km} / \mathrm{h}$ ). Most of cardiac arrests occurred when runners run under $9.9 \mathrm{~km} / \mathrm{h}$ for full marathon, and $10.0-14.9 \mathrm{~km} / \mathrm{h}$ for half-marathon. From this result, running with $10.0 \mathrm{~km} / \mathrm{h}$ at the beginning of the second half of the race was the highest risk. We need to take this into consideration for the future medical coverage during a marathon.

Compared to $29 \%$ of survival rate among the 59 cardiac arrests from the study by Kim et al. and Hart [3] [4], we had $54.0 \%$ of survival rate among 63 cases. The survival rate in Japan was higher than those in the U.S. The survival rate was improved every year as shown in the every-five-year division. Compared to 22.2\% (4/18 cases) between 1999 and 2003, we have had better result since AED was implemented for marathon races in 2004. The rate rapidly improved to 63.3\% (14/22 cases) between 2004 and 2008, and 69.6\% (16/23 cases) between 2009 and 2013. The crucial factor was the implementation of AED for marathon races, so the number of defibrillation administration by AED was increased under the situation of cardiac arrest during marathon races. In fact, in comparison to zero cases between 1999 and 2003, the case of defibrillation administration by AED was increased to eight cases between 2004 and 2008, and 12 cases between 2009 and 2013.

In cardiac arrests where bystander CPR was performed on the scene, the survival rate after one-month was 95.0\% (19/20 cases) of cardiac arrests treated with defibrillation, and $47.1 \%$ (8/17 cases) for cardiac arrest treated without defibrillation. There was two times more difference, and a statistically significant difference was found $(p<0.05)$. Also, defibrillation was given in the $83.3 \%$ of the cases where AED was applied. From this result, a cardiogenic cause was accounted for the majority of cardiac arrest during marathon races. Kuroyanagi et al. reported $81 \%$ of sudden death in sports in Japan was caused by a heart-related disease [1]. In other countries, researchers reported that heart-related disease is the majority of cause of cardiac arrest during marathon races [7] [8] [9].

We did not examine the risk of cardiac arrest and the reduction factors in our study, there are several studies indicating the importance of screening prior to the race and the efficiency of taking prophylactic Aspirin [10] [11]. Cardiac arrest could be occurred in marathon even with adequate prevention, so creating the medical support systems is needed to handle sudden cardiac arrest rapidly.

\section{Conclusion}

We analyzed the incidence rate of cardiac arrest during marathon races in Japan, 
and the number of cardiac arrests occurred in Japan during the past 15 years. The incidence of cardiac arrest during marathon races in Japan was 2.18 per 100,000 participants. Runners would go into cardiac arrest run at a speed of 10 $\mathrm{km} / \mathrm{h}$ and the most cases occurred in the second half of a race.

Also, $83 \%$ of cardiac arrests were shown as shockable rhythm and could be able to deliver defibrillation by AED. We found $95 \%$ of the survival rate after one-month when both bystander CPR on the scene and defibrillation by AED were administered. Since 2004, the use of AED by citizens was permitted and the survival rate was rapidly improved during marathon races. We think the reason behind is increased public access defibrillation (PAD) along with the implementation of AED at marathon races.

We expect higher survival rate due to conducting $\mathrm{PAD}$ on the scene. We also need to take risk factors into consideration for medical coverage on marathon races, especially the location and a time period. Thus, we need to create a medical support system that would be able to perform bystander CPR earlier and PAD for runners.

\section{Acknowledgements}

We express our extraordinary respect for all marathon staff in Japan for their efforts.

\section{Contribution}

TS carried out the all studies, statistical analysis, and drafted the manuscript. HT participated in the design of the study, and performed the statistical analysis. HT performed the statistical analysis and drawing figures and tables. ST conceived of the study, and participated in its design and coordination. TK advised and assisted in the planning of this paper and ST helped to revise the manuscript. All authors read and approved the final manuscript.

\section{References}

[1] Kuroyanagi, K., Matsuo, Y., Kojimahara, M., et al. (2002) Sudden Death during Exercise. The Journal of Japanese Society of Clinical Sports Medicine, 10, 479-489.

[2] Manabe, T. and Yamasawa, F. (2011) Toward a Safer Road Race: New Survey of Medical Committee, Japan Association of Athletics Federations. Sinzo, 43, 198-203.

[3] Kim, J.H., Malhotra, R., Chiampas, G., et al. (2012) Cardiac Arrest during LongDistance Running Races. The New England Journal of Medicine, 366, 130-140. https://doi.org/10.1056/NEJMoa1106468

[4] Hart, L. (2013) Marathon-Related Cardiac Arrest. Clinical Journal of Sport Medicine, 23, 409-410. https://doi.org/10.1097/01.jsm.0000433155.97054.c8

[5] Tunstall Pedoe, D.S. (2007) Marathon Cardiac Deaths. The London Experience. Sports Medicine, 37, 446-450. https://doi.org/10.2165/00007256-200737040-00046

[6] Waite, O., Smith, A., Madge, L., Spring, H. and Noret, N. (2016) Sudden Cardiac Death in Marathons: A Systematic Review. The Physician and Sportsmedicine, 44, 79-84. https://doi.org/10.1080/00913847.2016.1135036 
[7] Joggerst, S., Monge, J., Uribe, C., Sherron, S. and Angelini, P. (2014) Sudden Cardiac Arrest at the Finish Line: In Coronary Ectopia, the Cause of Ischemia Is from Intramural Course, Not Ostial Location. Texas Heart Institute Journal, 41, 212-216. https://doi.org/10.14503/THIJ-12-2867

[8] Beutler, J., Schmid, E., Fischer, S., Hürlimann, S. and Konrad, C. (2015) Plötzlicher Herztod beim Stadtmarathon [Sudden Cardiac Death during a City Marathon Run]. Der Anaesthesist, 64, 451-455. https://doi.org/10.1007/s00101-015-0043-5

[9] Mues, C., Scherf, L., Strasser, R.H. and Ibrahim, K. (2013) Survived Sudden Cardiac Death in a Young Marathon Runner: Cardiac Ischemic Event Attributed to an Interarterial Course of the Right Coronary Artery. Circulation, 128, e104-e106. https://doi.org/10.1161/CIRCULATIONAHA.113.001418

[10] Schwellnus, M.P. (2017) Premarathon Evaluations: Is There a Role for Runner Prerace Medical Screening and Education to Reduce the Risk of Medical Complications? Current Sports Medicine Reports, 16, 129-136. https://doi.org/10.1249/JSR.0000000000000366

[11] Siegel, A.J. (2012) Pheidippides Redux: Reducing Risk for Acute Cardiac Events during Marathon Running. The American Journal of Medicine, 125, 630-635. https://doi.org/10.1016/j.amjmed.2011.11.008

\section{Scientific Research Publishing}

Submit or recommend next manuscript to SCIRP and we will provide best service for you:

Accepting pre-submission inquiries through Email, Facebook, LinkedIn, Twitter, etc. A wide selection of journals (inclusive of 9 subjects, more than 200 journals)

Providing 24-hour high-quality service

User-friendly online submission system

Fair and swift peer-review system

Efficient typesetting and proofreading procedure

Display of the result of downloads and visits, as well as the number of cited articles

Maximum dissemination of your research work

Submit your manuscript at: http://papersubmission.scirp.org/

Or contact ijcm@scirp.org 